\section{Reorganization of the National Research Council}

The National Research Council-which organizes studies for the National Academy of Sciences and National Academy of Engineering and which is governed jointly by the two Academies and the Institute of Medicine of the National Academy of Sciences-is being restructured.

Organized for many years by divisions corresponding to the scientific disciplines, the National Research Council in 1972 was reorganized into assemblies, intended to concentrate on fields of study, and commissions, intended to examine public problems that required the attention of several disciplines. As assembly and commission programs developed, the distinctions faded.

Last month, first steps were taken towards putting a new, simpler structure in place. The National Research Council as reorganized would include initially:

A commission on behavioral and social sciences and education; a commission on engineering and technical systems; a commission on physical sciences and (natural) resources; an office of fellowships and scientific personnel; an office of international activities; a transportation research board; and several units not yet reorganized.

Still pending were decisions on organizational arrangements for biology and life sciences, agriculture, and studies of human health and medical sciences in the National Research Council and Institute of Medicine; meanwhile, the Institute of Medicine, Assembly of Life Sciences, and Board on Agriculture and Renewable Resources (formerly part of the old Commission on Natural Resources/ were to continue as currently organized.

The National Research Council reorganizational problems not yet resolved were pending before the Research Council's Governing Board and the councils of the Institute and Academies.

\section{NORDA leads international study of Mediterranean gyre}

A team of ocean researchers from the Naval Ocean Research and Development Activity (NORDA), with assistance from France and Spain, is studying a large circulation feature in the waters of the Alboran Sea, the westernmost part of the Mediterranean Sea.

The feature, a clockwise circular flow of water called a gyre, has a diameter of $100 \mathrm{~km}$. Formed by the water current flowing through the Strait of Gibralter from the Atlantic Ocean, the gyre is nestled between the coasts of Spain and Morocco.

The purpose of the study is to learn more about the ways oceanic flows behave near straits in general, as well as to learn about the strategically important Strait of Gilbralter region, in particular.

The project is being funded by the Office of Naval Research (ONR). The team is headed by NORDA principal investigators Thomas Kinder and Harley Hurlburt, Paul LaViolette and, representing ONR, Dennis Conlon.

A computer-generated numerical model of the flow dynamics of the gyre is presently being fabricated by Hurlburt and Ruth Preller of the JAYCOR Corporation. It will serve as the basis for the design of a cooperative field experiment, scheduled for this summer.

Satellite imagery of the area, beginning with data acquired from the October 1981 Space Shuttle Flight and continuing into this year, is being analyzed. The analysis of these images, supplied by the French Space Agency at Lannion, also contributes to the planning for the field work.

USNS Bartlett will be placing five current meter moorings near the Strait of Gibralter in June. In October, the Bartlett, under the command of the U.S. Naval Oceanographic Office, will return to the area and take temperature and salinity profile readings from the meters, in cooperation with ships of the Spanish Institute of Oceanography and Hydrographic Service of the Spanish Navy.

NORDA's Henry Perkins and Kim Saunders will be aboard the Bartlett acquiring data from a unique profiler they developed; and Ron Holyer and Bob Arnone, also of NORDA, will be making water column measurements.

Additional support for the project will come from personnel of the U.S. Navy Environmental Prediction Research Facility, who will be making meteorological measurements; from the National Oceanic and Atmospheric Administration's Wave Propagation Laboratory at Boulder, Colo., who will operate their shore-based, current measuring radar; and from the Spanish Institute of Oceanography, who will be making biological measurements in the waters of the area.

After the data acquired are compiled and analyzed, the investigators hope to improve their model and to better relate remote sensing images to the flow of the gyre. Increased understanding of the gyre formation and behavior should lead to better forecasting and monitoring of oceanic conditions near Gibralter and to general improvements in experiments and surveys in the waters near straits.

\section{Acid rain study in Wisconsin}

Dairyland Power Cooperative, acting on behalf of the Wisconsin Acid Deposition Joint Technical Review Committee, has contracted with Chas. T. Main, Inc. (MAIN) to conduct a twoyear climatological study and meteorological trajectory analysis of Wisconsin acid precipitation. The Committee is an organization of Wisconsin utilities and regulatory agencies. Utility members of the committee are: Wisconsin Electric Power Company, Wisconsin Public Service Company, Dairyland Power Cooperative, Lake Superior District Power, Northern States Power Company, Madison Gas \& Electric Company, Wisconsin Power \& Light Company, and Upper Peninsula Power Company. The participating state agencies are the Wisconsin Public Service Commission and the Wisconsin Department of Natural Resources.

The Committee is sponsoring a comprehensive research program on the causes and effects of acid deposition in Wisconsin. The objective of the climatological and meteorological trajectory studies is to identify the source regions of precursors of acid deposition monitored in Wisconsin. In-state versus outof-state contributors are to be distinguished to the extent possible.

MAIN will be using two state-of-the-art meteorological trajectory models for this study. One is MAIN's moist isentro- 
pic trajectory analysis model that traces the movement of air parcels throughout the complex precipitation mechanisms in large storms. Another is a computerized trajectory model developed by the National Oceanic and Atmospheric Administration. These trajectory models will be used to attempt to identify the source regions of precursors to acidity measured in Wisconsin precipitation during the 30 events designated as case studies.

The study also includes a climatological approach to assessment of precipitation acidity. The precipitation data will be analyzed for the relationship of acidity to chemical and meteorological factors. Also, precipitation chemistry data will be analyzed relative to weather type using satellite and radar data together with conventional weather observations.

At the conclusion of this two year study, MAIN will attempt to identify the probable source regions of the precursors of acid precipitation in Wisconsin and, as far as possible, differentiate in-state from out-of-state contributors to the monitored acid precipitation.

\section{LPA and APG to join}

At the invitation of Imperial College, the Laboratory for Planetary Atmospheres (LPA), University College London (UCL), is being integrated with the Atmospheric Physics Group (APG) to form a single teaching and research unit. This integration will take place in August 1982. The existing Imperial College group has active research activities in cumulonimbus dynamics and climate modeling. The UCL group will complement these studies by the introduction of satellite meteorological investigations of the atmospheres of the Earth and planets using sophisticated image processing techniques. The new group will then possess a balanced research program in both the observational and the interpretative aspects of atmospheric physics. It will be located at Imperial College and headed by Garry E. Hunt.

\section{Oceanographers to study puzzling "rings" spawned by Gulf Stream}

The National Science Foundation (NSF) recently announced that scientists have launched a study of puzzling masses of water that spin off the Gulf Stream and become swirling oases of warm water in the cold waters off the northeastern coast of the United States.

The rings of warm water, trapped by strong currents, range between 160 to $320 \mathrm{~km}$ in diameter and have important effects on the coast.

Approximately 60 scientists will be on board four ships that are scheduled to leave Woods Hole Oceanographic Institution between 14 and 19 April 1982 for three weeks of research. Polar orbiting satellites and a National Aeronautics and Space Administration (NASA) aircraft will be used in the study.

The researchers will investigate how the warm water rings affect the coastal waters. The rings are known to carry tropical fishes from the Sargasso Sea area to waters off Long Island, where perplexed fishermen sometimes snare them in their nets. The rings also bring rich nutrients into the coastal waters, where they play a major role in marine productivity. After the rings drift into coastal waters they move back to open waters, carrying with them offshore pollutants. The rings, which behave much the same way as storms, also cause much damage to

\section{NEW - No. 445 \\ DIGITAL ANEMOMETER - HAND HELD}

This compact cup anemometer, incorporating a Hall-effect transducer and C-MOS circuit, is designed to provide a liquid crystal display of the average wind speed taken over a 10 sec. sampling time - - for many applications this is a more important measure of wind speed.

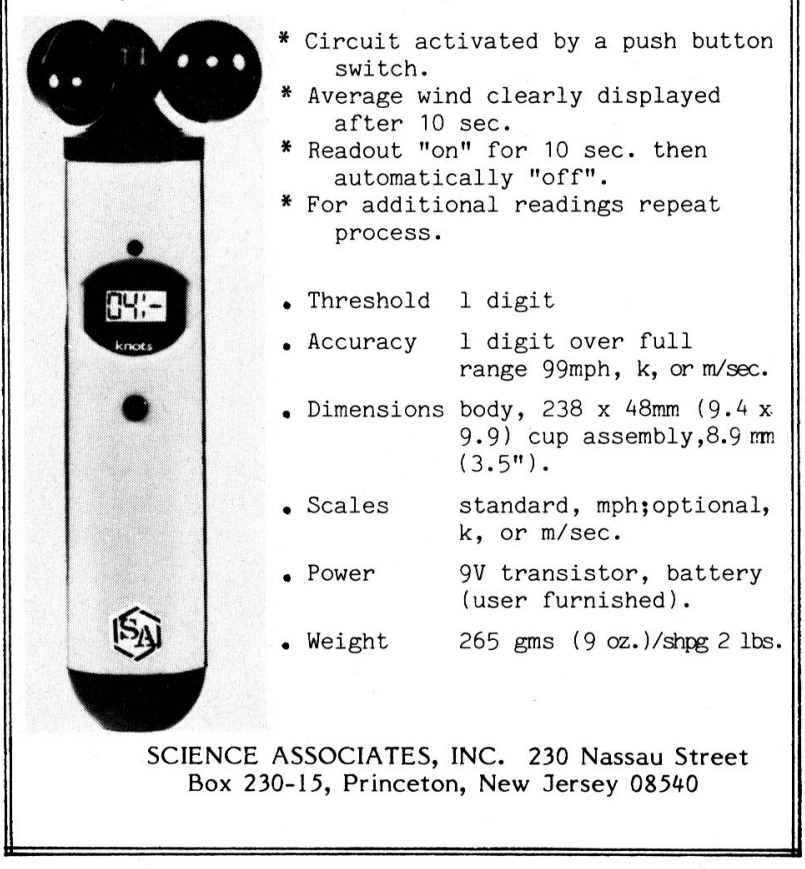

lobstermen's gear.

Biologists are interested in the rings because the enclosed waters provide a way of transporting entire ecosystems into a new and alien environment. How these ecosystems react to these new environments is important from a basic research point of view and also because knowledge about them should provide information important to the fisheries industry.

A common feature of the northwest Atlantic, Gulf Stream rings are spawned when huge eddies twist away from the main stream as it meanders away from North America at Cape Hatteras, N.C. Sometimes the meander executes a loop that gets pinched off the stream and moves away to become a swirling piece of the Gulf Stream in ocean waters that are different from those inside the captive ring.

If the ring forms to the north or west of the Gulf Stream, the trapped waters originate in the Sargasso Sea and the rings have a warm core and rotate clockwise; rings that form south or east of the stream carry away cold waters off the continental slope, rotate counterclockwise, and are called cold core rings.

The study, which began in April, will concentrate on warm core rings that are surrounded by strong currents of between 1-2 $\mathrm{m} \mathrm{s}^{-1}$. The scientists will study the physical, chemical, and biological processes inside these rings.

Three NSF-funded ships taking part in the April experiment are the $54 \mathrm{~m}$ Oceanus and the $75 \mathrm{~m}$ Knorr, both operated by Woods Hole Oceanographic Institution, and the $54 \mathrm{~m} \mathrm{En-}$ deavor, operated by the University of Rhode Island. The fourth ship in the experiment is the $57 \mathrm{~m}$ Albatross $I V$, operated by the National Ocean Survey for the National Marine Fisheries Service, both part of the National Oceanic and Atmospheric Administration (NOAA). 
The April cruise is the first of four scheduled to study warm core rings. A second cruise is scheduled for June, a third in August, and a fourth late in September 1982.

A preliminary study was made last September to gather data on which to base the April expedition, to test equipment and techniques, and to plan for coordinating the effort.

The steering committee for the warm core rings studies includes NSF-funded scientists Peter $\mathrm{H}$. Wiebe and Terrence M. Joyce of Woods Hole Oceanographic Institution, Glen Flierl of the Massachusetts Institute of Technology, James McCarthy of Harvard University, Dana Kester of the University of Rhode Island, and David Schink of Texas A\&M University.

\section{Spring snows set new record}

The late spring snowstorms that battered much of the United States set new records for snow cover, according to the National Oceanic and Atmospheric Administration (NOAA).

Imagery from weather satellites operated by NOAA's National Earth Satellite Service shows that from 5 to 11 April, 6.3 million square miles of North America were covered by snow, an all-time record for the 15 th week of the year. The extensive snow cover was more typical of a week in late February or early March than of early April, according to the satellite service.

The one million square miles of extra snow cover represents about $20 \%$ more than the 15 -year mean. The previous high snow cover for the 15 th week of the year was about 6 million square miles in 1979.

\section{Population shifts produce energy savings}

The United States saves a half billion dollars in energy costs annually because of population changes from 1970 to 1980 , the National Oceanic and Atmospheric Administration (NOAA) reports. The nation pays $\$ 1.3$ billion less each year in heating costs while paying an additional $\$ 800$ million in airconditioning costs, reflecting the past decade's population shift to the Sun Belt.

The calculations were made by NOAA's National Climatic Center in Asheville, N.C., on the basis of population-weighted heating degree days and cooling degree days-measurements of energy consumption used by the gas and electric industries. They showed a national decrease of 144 population-weighted heating degree days, amounting to a three percent annual savings in heating energy. At the same time, there was a national increase of 62 cooling degree days, amounting to a five percent rise in air-conditioning costs.

If the relative population in the Sun Belt continues to increase, NOAA points out, the savings in heating costs will gradually be overtaken by increased costs for air conditioning.

The calculations used census figures showing the changes in regional percentages of national population based on the 1970 and 1980 censuses. In those 10 years, population percentage decreases were shown in New England, down 0.38\%; Middle Atlantic, down $2.06 \%$; East North Central, down $1.41 \%$; and West North Central, down $0.44 \%$.

During the same years, the regions showing increases in the percentage of national population were South Atlantic, up $1.24 \%$; East South Central, up 0.17\% ; West South Central, up $0.99 \%$; Mountain, up $0.97 \%$; and Pacific, up $0.92 \%$.

\section{National marine pollution plan seeks ocean dumping studies}

As waste increases and places to put it decrease, research into possible effects of more ocean dumping becomes urgent, according to the National Oceanic and Atmospheric Administration (NOAA) in a National Marine Pollution Program Plan issued recently.

The five-year plan, required by the National Ocean Pollution Planning Act of 1978, finds that sewage waste disposal in particular is a growing problem as the population increases. "Pressure is mounting to allow continued and increased disposal of sewage sludge in the oceans," the plan says.

It also calls for more study of ocean dumping of dredged material and industrial waste, much of which is toxic, to see how such activities may best be carried out.

To make management decisions, the plan says, a conceptual model to assess the risks and impacts of ocean dumping options should be developed and applied in a specific region to assess its usefulness and the feasibility of a regional approach.

The plan was drawn up by the Interagency Committee on Ocean Pollution Research, Development and Monitoring.

An earlier five-year plan was issued by the Committee in the fall of 1979. "The emphasis on municipal waste disposal in the new plan represents a substantial change from the first plan," said Anthony Calio, chairman of the committee and deputy administrator of NOAA. "This reflects a change in public attitude-ocean dumping is now considered by many to be preferable to land dumping. We must find ways to use the oceans effectively as a waste repository."

The plan also recommends that some Outer Continental Shelf oil and gas leasing research be diverted from pre-lease environmental studies to post-lease monitoring, aimed at measuring the subtle effects of oil and gas developments over long periods of time. Federal research on petroleum pollution in the marine environment represents about $25 \%$ of the total Federal expenditure.

An interagency planning group is being formed to coordinate the long-term monitoring program.

Other relatively high priority areas listed by the plan are accidental discharges of oil and hazardous materials, nonpoint source pollution (such as agricultural runoff), and increased coal use as an emerging problem (disposal of fly ash and related activities will cause mounting problems as coal use is increased).

Areas of relatively low priority in the context of national marine pollution problems-either because they do not pose problems or because the problems are being adequately addressed-are bring disposal, sand and gravel mining deep seabed mining, and ocean-thermal energy conversion. 